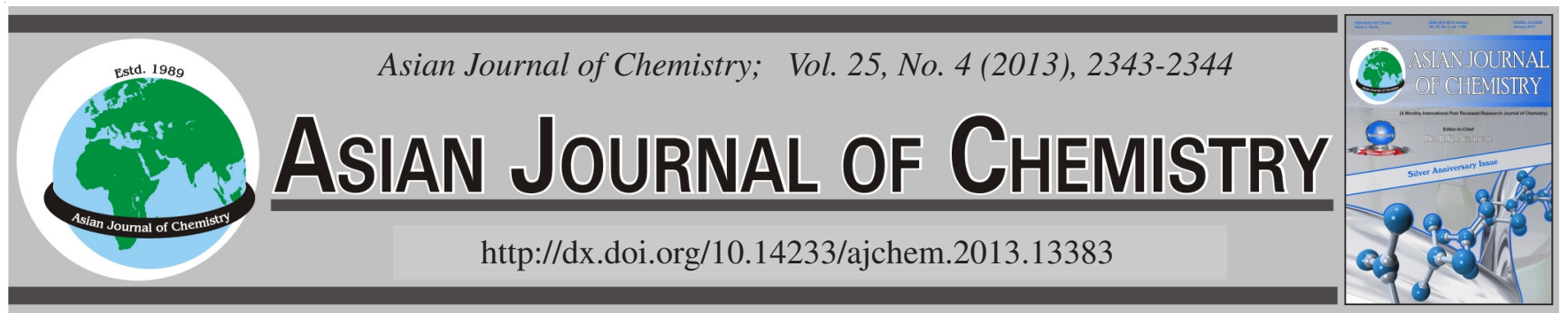

NOTE

\title{
Atomic Absorption Spectrophotometric Determination of Potassium Content of Soil and Leaf of Camellia oleifera from the Main Producing Areas of Guangxi, China
}

Hang Ye, Kaixiang Li*, Naiyan Zhang, Zepeng Jiang, Wenjun Zeng and Yingying Xia

GuangXi Forestry Research Institute (GFRI), Nanning city 530002, Guangxi Province, P.R. China

*Corresponding author: E-mail: 1kx202@yahoo.com.cn

(Received: 4 January 2012;

Accepted: 31 October 2012)

AJC-12352

The development of Camellia oleifera has a very important role on promoting integrated mountain development and the employment of rural income in Guangxi province. The concentrations of potassium in tea leaves and soils from ten major Camellia producing areas in Guangxi were measured by atomic absorption spectrophotometry. The results showed that most of the soils in central and northern Guangxi province were very deficient for potassium, so potassium deficiency is an important reason leading to low yield of Camellia forest in central and northern Guangxi.

Key Words: Camellia oleifera, Soil, Leaf, Potassium, Atomic absorption spectrophotometry.

Camellia oleifera is a species of tree which has a certain collectively cultivated area, belong to Camellia genus, whose seed oil content is high ${ }^{1}$. Camellia oleifera is originated in China is called one of the world's four major woody oil plants as olive, oil palm, coconut. Camellia oleifera is one of the health-based cooking oils focused on promoting by FAO, whose unsaturated fatty acid content is more than $90 \%$, known as the "Oriental olive oil."2. The development of Camellia oleifera has an important role on promoting integrated mountain development, promoting the employment of rural income and safeguarding national grain security and improve people's health ${ }^{3}$.

Guangxi province has $300,000 \mathrm{hm}^{2}$ Camellia forest, the average annual yield of oil per $667 \mathrm{~m}^{2}$ is less than $5 \mathrm{~kg}$ and income per $667 \mathrm{~m}^{2}$ is less than 300 , which has been a serious impediment to the development of Camellia oleifera one of the most important reasons resulted to the low yield of Camellia forest is poor soil due to lack of management ${ }^{4}$. To promote Camellia production, the concentrations of potassium in tea leaves and soils from major Camellia producing areas in Guangxi were measured.

Sampling sites: Samples were collected from Cenxi, Napo, Babu, Bama, Zhaoping, Taine of central Guangxi and Rongan, Rongshui, Sanjiang, Longsheng of northern Guangxi on July in 2011 , the range is latitude $23^{\circ} 12^{\prime}-25^{\circ} 52^{\prime}$ and longitude $105^{\circ} 50^{\prime}-111^{\circ} 12^{\prime}$ between. The soils of Cenxi and Zhaoping are the red loam and soils from Sanjiang and
Rongshui are sandy loam, other six soils are all yellow loam (Table-1).

Sampling method: The soils and leaves were collected by random sampling method. The soils were collected from depth of 0-40 cm, mature leaves were collected on normal growth of Camellia plants in different directions. Samples were mixed by point, seal back to the laboratory for determination ${ }^{5-7}$.

Determination of potassium: Soil available potassium was determined by ammonium acetate extraction-atomic absorption spectrophotometry. Total potassium of leaves was determined by atomic absorption spectrophotometry with nitric acid-perchloric acid digestion ${ }^{5-8}$.

The results showed that the available potassium concentrations in sampling soils are all very low. The available potassium concentration in Napo soil was lack grade; Babu, Tiane and Rongan were the very lack grade; the other six soils were the extreme lack grade (Tables 2 and 3 ).

The results showed that leaf total potassium of Camellia oleifera from northern Guangxi ranged from 3509-4658 mg/ $\mathrm{kg}$ and that from central Guangxi is $4659-8723 \mathrm{mg} / \mathrm{kg}$ which is obviously higher than central Guangxi.

The previous research proved that potassium is a potential limiting factor for the growth of Camellia oleifera ${ }^{6}$ and soil potassium levels of high-yielding Camellia oleifera forest were significantly higher than low-yield Camellia oleifera forest ${ }^{4}$, in this paper the results showed that most of the soils in central and northern Guangxi province were very deficient for 
TABLE-1

BASIC SITUATION OF SAMPLING SITES

\begin{tabular}{|c|c|c|c|c|c|}
\hline \multirow{2}{*}{ Region } & \multicolumn{2}{|c|}{ Sampling sites } & \multicolumn{2}{|c|}{ Latitude and longitude } & \multirow{2}{*}{ Soil type } \\
\hline & County & Village & North latitude & East longitude & \\
\hline \multirow{6}{*}{ Central Guangxi } & Cenxi & Liuchen & $23^{\circ} 12^{\prime}$ & $110^{\circ} 43^{\prime}$ & Red loam \\
\hline & Napo & Pingmeng & $23^{\circ} 22^{\prime}$ & $105^{\circ} 50^{\prime}$ & Yellow loam \\
\hline & Babu & Baizhu & $23^{\circ} 49^{\prime}$ & $111^{\circ} 12^{\prime}$ & Yellow loam \\
\hline & Bama & Fuxiang & $24^{\circ} 08^{\prime}$ & $107^{\circ} 15^{\prime}$ & Yellow loam \\
\hline & Zhaoping & Zouma & $24^{\circ} 11^{\prime}$ & $110^{\circ} 55^{\prime}$ & Red loam \\
\hline & Tiane & Pingli & $24^{\circ} 51^{\prime}$ & $107^{\circ} 29^{\prime}$ & Yellow loam \\
\hline \multirow{4}{*}{ Northern Guangxi } & Rongan & Zhuyu & $24^{\circ} 53^{\prime}$ & $109^{\circ} 34^{\prime}$ & Yellow loam \\
\hline & Rongshui & Dalang & $25^{\circ} 27^{\prime}$ & $109^{\circ} 25^{\prime}$ & Sandy loam \\
\hline & Sanjiang & Liangkou & $25^{\circ} 42^{\prime}$ & $109^{\circ} 28^{\prime}$ & Sandy loam \\
\hline & Longsheng & Sishui & $25^{\circ} 52^{\prime}$ & $110^{\circ} 07^{\prime}$ & Yellow loam \\
\hline
\end{tabular}

\begin{tabular}{ccccc}
\multicolumn{5}{c}{ TABLE-2 } \\
\multicolumn{5}{c}{$\begin{array}{c}\text { AVAILABLE POTASSIUM CONCENTRATIONS } \\
\text { OF SOILS AND LEAVES }\end{array}$} \\
\hline \multirow{3}{*}{ Region } & Sampling sites & Soil & Leaf \\
\cline { 2 - 5 } & County & Village & $\begin{array}{c}\text { Available K } \\
(\mathrm{mg} / \mathrm{kg})\end{array}$ & $\begin{array}{c}\text { Total K } \\
(\mathrm{mg} / \mathrm{kg})\end{array}$ \\
\hline \multirow{5}{*}{ Central } & Cenxi & Liuchen & 24.2 & 6655 \\
Guangxi & Napo & Pingmeng & 57.2 & 5808 \\
& Babu & Baizhu & 34.1 & 6655 \\
& Bama & Fuxiang & 22.0 & 8723 \\
& Zhaoping & Zouma & 23.1 & 5264 \\
& Tiane & Pingli & 30.8 & 4659 \\
\hline \multirow{3}{*}{ Northern } & Rongan & Zhuyu & 31.4 & 3630 \\
Guangxi & Rongshui & Dalang & 29.4 & 4658 \\
& Sanjiang & Liangkou & 27.5 & 3872 \\
& Longsheng & Sishui & 9.9 & 3509 \\
\hline
\end{tabular}

TABLE-3

GRADING STANDARDS OF SOIL NUTRIENT CONTENT

\begin{tabular}{lcc}
\hline \multicolumn{1}{c}{ Grade } & Organic matters $(\%)$ & Available $\mathrm{K}(\mathrm{mg} / \mathrm{kg})$ \\
\hline 1 Very rich & $>4$ & $>200$ \\
2 Rich & $3-4$ & $150-200$ \\
3 Moderate & $2-3$ & $100-150$ \\
4 Lack & $1-2$ & $50-100$ \\
5 Very lack & $0.6-1$ & $30-50$ \\
6 Extreme lack & $<0.6$ & $<30$ \\
\hline
\end{tabular}

potassium and potassium is essential on the formation and enlargement of the fruit $^{9}$, so potassium deficiency is an important reason leading to low yield of Camellia forest in central and northern Guangxi, especially in northern Guangxi.

\section{ACKNOWLEDGEMENTS}

The authors thank the support of Guangxi Science and Technology Research Topics and New Product Trial: Integration and Demonstration of High Efficient Growing Technology of Camellia species (No. GKG10100012-1A). This work is also supported by National Project of Scientific and Technical Supporting Programsof the Eleventh 5-year Plan Period Funded by the Ministry ofScience \& Technology of China (No. 2009 BADB1B06).

\section{REFERENCES}

1. Y.Z. Chen, Good Germplasm of Camellia, Beijing: China Forestry Publishing House, p. 15 (2008).

2. M.H. You, J. Anhui Agric. Sci., 36, 6119 (2008)

3. Z.B. Jia, Forestry Economics, 10, 3 (2008).

4. J.S. Wu, Y.R. Zeng and Z.J. Li, J. Beijing Forestry Univ., 31, 203 (2009).

5. H.L. Wang, G.C. Chen, J.Z. Cao, N.Y. Zhang, Y. Zhang and B.C. Nong, Guangxi Forestry Sci., 39, 64 (2010).

6. D.N. Hu, K.H. Sun, F.L. Fan, F. Chen, D.K. Niu and X.M. Guo, Soils Fertilizers, 6, 20 (2005).

7. Y.J. Wang, X.S. He, C. Gong, X.L. Lei and L.C. Xu, Nonwood Forest Res., 28, 55 (2010).

8. X.J. Pan and H.B. Hou, J. Hunan Forestry Sci. Tehnol., 29, 73 (2002).

9. X.M. Deng, Z.H. Han and S.H. Li, Fruit Trees Biology, Beijing: Higher Education Press, p. 116 (1999). 